\title{
Community responses to tourism and crime
}

\section{Hooton, $\mathrm{N}$}

http://hdl.handle.net/10026.1/4732

Crime Prevention and Community Safety

All content in PEARL is protected by copyright law. Author manuscripts are made available in accordance with publisher policies. Please cite only the published version using the details provided on the item record or document. In the absence of an open licence (e.g. Creative Commons), permissions for further reuse of content should be sought from the publisher or author. 


\section{Community Responses to Tourism and Crime}

\section{Paul Brunt and Natalie Hooton ${ }^{1}$}

1 Paul Brunt is Head of Marketing, Tourism and Hospitality at the University of Plymouth, Drake Circus, Plymouth, PL4 8AA, UK pbrunt@plymouth.ac.uk. Natalie Hooton is a PhD student at the University of Plymouth

Tourism is known to bring about positive and negative changes to destinations. This paper explores how tourism business owners' lives and residents within the tourism area of an English seaside resort respond in their behaviour as a consequence of tourism-related crime and their fear of such crimes. Through a mixture of primary and secondary data analysis it is clear that crime in the case study area increases during the tourism season. The results suggested that these are changes in behaviour made by parking in different locations; socialising differently; bypassing specific streets at night; and carrying out additional security checks in the home. Perceptions of the destination and of criminal activity were found to vary in relation to occupation and involvement with the tourism industry, and there were associations with socio-demographic variables and the level of attachment to the town.

\section{Key words: Tourism; crime patterns; community responses}

\section{Introduction}

Tourism development has two main contexts, on one hand it is believed that tourism "like any other industry, contributes to the environmental destruction" of a destination, and on the other "given proper planning and management, tourism can enhance the environment and be a positive influence" (Walmsley, Boskovic and Pigram 1983:137). Positive changes include improved facilities and infrastructure, and negative changes include disruptions to community life through noise, pollution, litter, vandalism and crime. The extent of change is dependent on the tourist destination and the nature of tourism activity taking place, while the pace of development, size of the tourism industry and the importance of tourism to the local economy are also important elements. These fundamentals help to explain why community response to tourism can, for some, "be mirrored by an increasingly negative attitude towards tourists from the host community" (Brunt and Hambly 1999:26). The purpose of this paper is to explore how residents respond in their behaviour to tourism-related crime and their fear of crime within a traditional British seaside resort 
community. The following review will first analyse the relationships between tourism and crime, and assess the nature of host perceptions of tourism.

\section{Tourism and Crime}

Reviews within the subject area of tourism and crime have identified broad topics associated with published studies of the tourism and crime relationship. Included in these are: tourist areas as areas of high crime rates; tourists as victims; tourists as offenders; tourism generating higher levels of deviant or illegal activity; terrorism and tourism; as well as policy responses to tourism and crime (Ryan 1993; Brunt and Hambly 1999). Within the academic literature there are other linkages identified between tourist activity and crime including the crimes of locals against tourists, tourists against locals, offences that occur through the illegal servicing of demands created by tourists, and criminal activities that relate to the growth and development of a destination which exhibit a tourism-dependent economic base (Mathieson and Wall 1982; Chesney-Lind and Lind 1986; Kelly 1993; Brunt and Hambly 1999; Brunt, Mawby and Hambly 2000).

A constant theme in much of the research is the "lack of suitable information about victims and perpetrators" (Prideaux 1996:60). Moreover, there are issues with how crime can be measured and how the extent of tourism is quantified (Agarwal and Brunt 2006) as data on tourists at a local level are difficult to obtain and crime statistics can be suspect. For example, changes in the nature of law enforcement such as a police 'crackdown' can result in apparent increases in the crime statistics and language issues at international destinations can create fear of reporting tourist-crime incidents thus resulting in under-reporting.

Much less academic attention has been devoted to exploring the tourist as the offender, though it could be argued that badly behaved tourists have provided many newspaper column inches (Brunt and Davis 2006). In a review of two English seaside resorts, Brunt and Brophy (2004) focused on the behaviour of tourists and highlighted the probability that the nature of the deviant and criminal behaviour of tourists is related to the type of location. This can be influenced by how media portrays the image of the tourist destination. In summarising their study, Brunt and Brophy (2004) proposed a typology of tourists' deviant behaviour as shown in Table 1. 
Table 1: Typology of Deviant Behaviour

\begin{tabular}{|l|l|}
\hline Type of Tourist & Description \\
\hline Accidental Deviant & $\begin{array}{l}\text { Unintentional deviance. Predominantly younger adults. E.g. excessive } \\
\text { alcohol consumption leading to aggressive/violent behaviour towards } \\
\text { others. }\end{array}$ \\
\hline Situational Deviant & $\begin{array}{l}\text { Unplanned deviance. Age is usually irrelevant. However, the } \\
\text { opportunity to take drugs/see prostitutes becomes appealing as a 'one- } \\
\text { off' when visiting places where these acts are publicly on show or } \\
\text { tolerated. }\end{array}$ \\
\hline Intentional Deviant & $\begin{array}{l}\text { Planned deviance. Age is typically irrelevant. The tourist holidays in } \\
\text { places where he knows he can easily indulge in his desired deviant } \\
\text { activity. }\end{array}$ \\
\hline
\end{tabular}

Source: Brunt and Brophy (2004:9)

The broad categories are perhaps a limitation to this typology, but do provide a basis for further investigation and testing. In addition to these classifications, consideration needs to be given to the type and nature of the destination, as it is perceived that those destinations promoted as 'party' resorts, geared towards a young adult market, encourage a more 'hedonistic' type of tourist (Brunt and Brophy 2004; Agarwal and Brunt 2006) and such locations tended to experience higher crime rates (Prideaux 1996). Media reporting can effect and influence the image of a destination, and bad publicity can ultimately affect tourism demand (Brunt and Davis 2006). Further, the development and expansion of the night-entertainment industry and the size of a destination's drug sub-culture and 'hedonistic' lifestyle have been highlighted as contributing to higher levels of crime (Ryan 1993; Prideaux 1996; Brunt et al. 2000).

In terms of host community reaction to these issues, there is a need to distinguish between the social aspects of individuals and other issues such as gender, income, age and experiences of crime. This is important as the fear of crime varies across subgroups of the population, but is often higher amongst females than males (Garofalo and Laub 1978; Brunt and Shepherd 2004). Males show a higher victimisation rate while females show a higher level of fear, which is further positively associated with age; "as age goes up, victimisation rates decrease and the fear of crime increases" (Garofalo 1979:84). 


\section{Host Perceptions}

Host communities have mixed perceptions of tourism, tourists and tourism development (Brunt and Courtney 1999). This is dependent on the nature and importance of tourism locally and the hosts' level of interaction with the industry, their attitude and economic dependence to it, and the character of tourists (Carmichael 2000). Mathieson and Wall (1982) suggested that social and cultural impacts fall into three different categories; the tourist, the host, and the host-tourist relationship. However, whilst considering these categories it is important to "recognise that residents do not represent an homogenous group" (Brunt and Courtney 1999:498).

To understand the host-guest relationship it is important to note aspects of the nature of the encounter, as well as the reason for the encounter. This was also established within Tosun's (2002:233) study of host perceptions of tourism impacts where "social contact between individuals from different cultural backgrounds might result in negative attitudes, perceptions, and experiences" as a whole. Therefore the nature of these relationships is a major factor that influences the extent to which positive or negative perceptions are felt by local residents (Smith 1989).

Host-guest relationships have been explored by Krippendorf (1987) who suggested that host opinions were related to occupational group and level of interaction with the tourism industry. Five main categories of host type within a tourist destination were proposed: people who are in continual/direct contact with tourists; proprietors of tourist businesses; hosts in direct/frequent contact with tourists but only with partial income coming from the industry; locals who have no contact with tourists but only see them in passing, alike the early work of Doxey (1975) within the Irridex index model; and politicians and political lobbyists (Krippendorf 1987). Together these set a structure for analysis as supported by de Kadt (1979:50) who suggested that "encounters between tourists and the local inhabitants must be differentiated according to the stage of tourism development in which they occur and the type of tourist involved".

Within the published literature it is clear that extensive research has been conducted on resident attitudes to tourism development (Carmichael 2000; Gursoy, Jurowski and Uysal 2002; Tosun 2002; Perez and Nadal 2005) as a basis for understanding why residents perceive tourism impacts positively or negatively. As residents can influence the success or failure of the tourism industry, it is suggested that their estimations need to equal the benefits gained in return for a positive perception to be formed (Perez and Nadal 2005:927). When the exchange is balanced or in favour of the residents, tourism impacts are viewed positively, and only viewed negatively when exchange is non-favourable to the host community. 
Thus, the effects of tourism can include both positive and negative impacts, and these vary from place to place. The level of a residents' engagement with the industry and extent of encounters with tourists can influence attitudes, including those associated with tourism and crime. Attachment to the destination can also have an effect upon perceptions, with some residents (typically those with less attachment) becoming more critical and less enthusiastic over time (Lawson, Williams, Young and Cossens 1998:255). It is clear that the nature of the host-guest relationship, can affect the attitude and behaviour of the host population within a destination, whose reactions are diverse (Lindenberg, Andersson and Dellaert 2001:1010) and may be linked to the occupation/engagement with the industry and attachment to the destination. For some, the mere sight of tourists can induce behavioural changes, especially in the stagnation or decline stages of the development of the destination (Mathieson and Wall 1982:135). Despite the numerous studies that have focused upon residents' attitudes towards tourism development, Carmichael (2000:601) suggests that there is still "only a limited understanding of residents responses to the impacts of tourism".

Typically crime is viewed as a negative consequence of tourism development that affects the quality of life within a destination. Perceptions can be affected and exaggerated by a number of factors when consulting residents and their perceptions of criminal activity. As in a more general sense, attachment to and engagement with the industry, the distance from the place of residence to the location of tourists and crime hotspots can all influence opinions. Essentially a more critical and less enthusiastic attitude among residents occurs over time, which can influence the characteristics of residents' habits, their daily routines, social lives, beliefs and values (Andereck, Valentine, Knopf and Vogt 2005:1058). The extent to which tourism-related crime influences host community behaviour is less clear. Hence, due to the limited understanding of residents' responses, the study explores community responses and behavioural changes to tourism and crime, via a case study of an English seaside resort.

\section{Study Area: Newquay}

As a tourist destination, Newquay became known as a traditional seaside resort in Cornwall, England, which "attracts a high proportion of domestic staying visitors, who typically fall into the middle to older age brackets. These visitors have a tendency to encompass the lower socioeconomic groups and are more likely to visit in adult only groups" (Southwest Tourism 2005). Advertising campaigns for the resort have stated that "Newquay is the most popular holiday destination in Cornwall and the Surf Capital of the UK" (Anon 2008). The resort has also been described as "the capital of England's surfing scene with 11 beaches stretching over seven miles of 
golden sand, therefore it is not surprising that this one-time fishing village has transformed itself into the surfer's paradise" (Surf Newquay 2008). Thus, there has been a shift in the type of tourists Newquay attracts. This shift has transformed the resort from a traditional seaside resort into a more hedonistic 'party' town (Barton and James 2003) catering for the younger adult market. As a result, Newquay has succumbed to the fate of media attention as a destination for young adults to party, take drugs and drink to excess. Consequently, Newquay has become to be regarded as a crime 'hotspot' and is, therefore, an ideal location to explore the realities of the relationships between tourism, crime and the host community. Before any primary data collection was contemplated it was necessary to assess the level of crime and the type of offences that occur within the destination. To do this an examination of the population and crime figures was carried out, and is discussed below.

For the purpose of this study, secondary data were gathered through the Devon and Cornwall Police statistics. In addition the collections of both British Crime Survey (BCS) data and the Crime and Disorder Audit (CDA) figures for Restormel (the local authority district within which Newquay is based) were used. There were limitations for this analysis that needed to be addressed. There were concerns over how crime was measured and that the extent of tourism at a local level was difficult to obtain. Similarly other limitations may exist in that, "it is highly likely that tourists will face different considerations compared with locals in deciding whether or not to report crime" (Mawby 2000:112). Therefore, certain types of crimes against both tourists and the host population may go unreported. In addition there were difficulties in measuring accurate trends in police recorded crime.

\section{Population and Crime Figures}

The population of Newquay since the census in 2001 has fluctuated around 20,000 (Neighbourhood Statistics 2008). Although these figures date back to the last census, they serve as a comparable source for crime rate assessment figures. These comparable measures are displayed in Table 2. 
Table 2: Crime Rates and Population Figures

\begin{tabular}{|l|l|l|l|}
\hline & Population 2001 & $\begin{array}{l}\text { Total Crime Figures } \\
\text { for 2006/07 }\end{array}$ & $\begin{array}{l}\text { Crime Rate per 1000 } \\
\text { population }\end{array}$ \\
\hline $\begin{array}{l}\text { Newquay, Gannel } \\
\text { Ward }\end{array}$ & 6010 & 705 & 118 \\
\hline Restormel District & 100,000 & 39,880 & 40 \\
\hline Devon and Cornwall & $1,629,000$ & 74,905 & 46 \\
\hline
\end{tabular}

Source: Home Office (2008); Neighbourhood Statistics (2008)

From the analysis of these crime statistics it is evident that Newquay, and the ward of Gannel (where the main tourism facilities are located) has a higher overall crime rate per 1000 population than the rest of the local authority district and the jurisdiction of the Devon and Cornwall Constabulary. Newquay, however, is within the only county district that could be characterised as having mass tourism (MRS 2004). Therefore it could be suggested that the actual crime rate per 1000 population (based on the resident population) is not reflective of the situation at the location, in its failure to acknowledge the additional 'population' of tourists. This is important to note as the relationships between tourism and crime have a similar season to the tourism industry (Mathieson and Wall 1982). This relates to the Walmsley et al. study (1983:154), which noted that "the peaks and troughs in the occurrence in crime coincided with the highs and lows in tourist activity". Therefore gaining an insight into the number of tourists, and having an accurate figure of the resident plus tourist populations would enhance the reliability of this study as the precise number of tourists within the destination was unknown, given that no other detailed data collection is routinely undertaken.

Based upon assumptions of occupancy levels and the number of available bed spaces within the destination, it is suggested that the population of Newquay may increase fourfold. Although this figure is surrounded by speculation, it would suggest that the total crime rate per 1000 population (based on this total figure) is considerably lower than first perceived. Regardless of this, there are no official statistics for such an analysis and there are additional limitations that would need to be considered to ensure accuracy. These limitations would need to include seasonal variations of population and crime rates alongside unreported crime rates in relation to the local and the visitor perspectives. These issues could provide the basis for further investigation. However for the purpose of this study such elements were not further examined.

Another source of secondary data is the Crime and Disorder Audit (CDA), which provides information on the levels of crime within Restormel district and offers information on what the 
local population thinks about crime and disorder in the area (MRS 2004). Newquay was identified as a tourist resort well known for its surfing and was also highlighted as housing the "most disadvantaged ward" in the district, coupling low levels of car ownership with levels of high unemployment (MRS 2004:13). Newquay was also emphasised as being the only district characterised by mass tourism "with young singles comprising a significant section of the market, partly but not exclusively through the appeal of surfing and special events" (MRS 2004:15). In addition to this, it was perceived that "visitors may contribute to local crime and disorder problems" (MRS 2004:15).

Putting the various secondary data sources together (MRS 2004:26; Home Office 2008), the following observations can be made:

- The tourist areas of Newquay have a higher crime rate per 1000 population than the averages for the Restormel District and for Devon and Cornwall;

- There is perceived feeling of a lack of safety among the resident population;

- Crime is most common at night with fear much lower in the daytime;

- There is a perceived link between tourism and crime;

- Crime and disorder are more common within the summer months; and

- Traffic congestion, anti-social behaviour and other incivilities are ranked above crime estimations and concerns of the local population.

\section{Methods}

The logic and rationale for this case study was based on the aim to identify responses in host's behaviour as consequence of tourism-related crime and their fear of such crime. Following the secondary data analysis, primary data were collected in three stages. The first stage was a series of observational studies over a four-week period that helped to provide knowledge of the destination area and insights into behaviour patterns within the resort. These observations were then used to identify grounds for the construction of a quantitative questionnaire, distributed to local residents and business owners as the second stage of data collection. The third stage consisted of a small number of depth interviews with key stakeholders and residents of Newquay. The reason for conducting a qualitative stage after a quantitative enabled the respondents to comment on some of the preliminary findings within the interview, and for purposes of triangulation, allowed the phenomena to be viewed from more than one source (Decrop 1999; Davies 2003). 
This integration of methods of data collection provided a number of benefits and limitations. The main advantage was being able to observe behaviour of a situational nature (Veal 1992), and the environment of the resort directly as opposed to only being inferred or remembered. Observational logs were developed to enable general orientation (Moser and Kalton 1971) and systematically observe a range of dimensions in and of the setting first-hand.

The questionnaire was mailed to members of a local association of tourism and commerce, the NCCT (Newquay Chamber of Commerce \& Tourism). A total of 700 questionnaires were posted. 500 were inserted within the Newquay Business News specifically targeted at the NCCT members, and a further 200 were delivered by hand to a selection of resident properties within the tourism areas of the town. These were selected in relation to their location with the hot spot crime areas identified within the CDA report for Restormel.

Thus the survey was specifically aimed at those either directly involved in the tourism industry or living close to the main tourism areas of the town. This targeted approach has both benefits and weaknesses. The use of a business directory to target local tourism businesses is a fair means of achieving a reasonable spread of this sector of the community. The further identification of private residents within the 'tourism district' provides a pragmatic means of accessing potential respondents who were likely to be most affected by tourism in their daily lives and would therefore, hopefully, be in a position to provide meaningful comment. It was understood that this sample could not be said to be representative of the whole population of Newquay.

Depth interviews were the third method of data collection used in this study, in an attempt to ensure a rounded perception of the host's opinions in Newquay. Eight interviews were undertaken of key stakeholders within the town. The interviews adopted a semi-structured approach to questioning, as all respondents were asked the same set of questions about the research topic. This form of interview was identified as being the best suited to test the already established results of both the observational logs and the quantitative analysis. The 'Framework Method' was used to analyse the qualitative data in the form of interview transcripts (Brunt 1997) and the selection of interviewees was in line with Krippendorf's (1987) occupational structure, based on the respondent's engagement with the tourism industry.

\section{Findings}

The results of the data collection can be summarised through the charting of themes from both the observational logs and depth interviews, relating to how the host population regard change in behaviour to accommodate for their experiences and fear of crime in Newquay. A descriptive 
summary for the quantitative study $(\mathrm{n}=80)$ was also possible. Selected findings that are indicative of the general themes found for each of the methods of data collection are summarised in the following tables $(3,4,5$ respectively). 
Table 3: Summary of comments from field note analysis of observations

\section{Theme: General Atmosphere}

\begin{tabular}{|l|l|}
\hline Day & "Feel as though I am sat amongst it all" \\
\hline Night & "It has changed considerably" \\
\hline & "There is something about this location that I am not at ease with" \\
\hline & "You can sense the potential of this place and the problems which could be caused" \\
\hline & "It has progressively got busier" \\
\hline & "I don't really feel welcomed at all within the bar"
\end{tabular}

\section{Theme: Location}

Day $\quad$ "People... are congregated on the pavement causing an obstruction to others"

"Seems to be the meeting place for everyone"

Night "The terrace outside has enough people on it to suggest a maximum capacity"

"You could describe this place as the bottleneck of the area"

\section{Theme: Type of People}

Day $\quad$ "there is... a distinction between the people sat inside and those lazing outside"

\begin{tabular}{|l|l|}
\hline & "There are a variety of groups about...hens and stags to youthful groups" \\
\hline & "Boy racers" \\
\hline Night & "There are also families evident" \\
\hline & "Definitely not family orientated"
\end{tabular}

\section{Theme: Group Sizes}

\begin{tabular}{|l|l|}
\hline Day & "Group size is larger (5-10)" \\
\hline & "More groups appearing... adding to the male dominance of the area" \\
\hline Night & "Groups galore" \\
\hline & "Hoards that are now within the establishment" \\
\hline
\end{tabular}

\section{Theme: Distinction between the sexes}

\begin{tabular}{|l|l|}
\hline Day & "No sign of a woman anywhere, just men" \\
\hline & $\begin{array}{l}\text { "There is a definite war of the sexes...more males present than females... there is about a } 70 \text { to } 30 \\
\text { ratio of males to females" }\end{array}$ \\
\hline "Sense the male dominance in the air" \\
\hline & "Heaps of underage looking girls...but no guys" \\
\hline Theme: Traffic Congestion \\
\hline Day & "Very busy as far as the traffic is concerned" \\
\hline & $\begin{array}{l}\text { "Traffic seems to becoming more of a problem with more deliveries, and more traffic in general is } \\
\text { passing by" }\end{array}$ \\
\hline Night & "The traffic is...is not congested" \\
\hline Theme: & "There seems to be an abundance of Taxis turning up" \\
\hline Dayti Social Behaviour & $\begin{array}{l}\text { "With...the amount of alcohol people seem to be consuming, you can't help but think that there } \\
\text { could be trouble later" }\end{array}$ \\
\hline & "A lot of people drinking already" \\
\hline Night & $\begin{array}{l}\text { "A young is already a police presence... It is not even 12 o'clock" } \\
\text { it would have intimidated me and if I was with my family, I would have been highly offended by } \\
\text { the naked man" }\end{array}$ \\
\hline & "Many people have started chanting back and forth and no one is attempting to shut them up" \\
\hline & $\begin{array}{l}\text { "The drinking is heavier than expected and once again binge drinking is the order of the day" } \\
\text { residents" }\end{array}$ \\
\hline
\end{tabular}


Table 4: Quantitative Study - description of respondents and their opinions

- $57.5 \%$ of respondents were female, aged between $55-64$, live as a couple with a family $(27.5 \%), 66.3 \%$ and are home owners/occupiers

- The majority (58\%) of respondents both lived and worked within Newquay

- The average residency was 22 years

- $38.5 \%$ of the respondents viewed the crime rate as increasing a lot more over the years they had experienced the town

- $77.5 \%$ agreed or agreed strongly with the comment that crime is associated with tourism

- The main annoyance of local residents included rubbish and littering (58.8\%), as well as drunk and rowdy behaviour $(65 \%)$

- Offenders were classified as unintentionally committing crimes

- $67.5 \%$ of respondents stated that they change their behaviour to accommodate for their fear of crime

- The most prevalent changes in behaviour included parking in different locations (50\%), socialising in different locations $(59.3 \%)$, bypassing specific streets in the evening $(68.5 \%)$, and carrying out additional security checks in the home (57.4\%)

- $54.7 \%$ of respondents' perceived crime as a seasonal problem and most prevalent in the summer months, thus identifying crime as a specific problem in relation to the tourism season $(56.6 \%$ ) as $62.5 \%$ of respondents highlighting tourists as the cause of locals changing their behaviour

- Zone A (Gannel ward) was identified as; having the highest crime rates (80\%); being most dangerous $(70 \%)$; most unsafe to walk through alone $(73.8 \%)$; most unsafe to drive through $(68.8 \%)$; the zone automatically avoided in the summer (72.5\%); the location where residents choose not to park their car $(62.5 \%)$; the zone in which people's fear of crime is at the highest $(70.0 \%)$.

- Zone C (38.8\%) and E (38.8\%) (residential areas away from the tourism zone) were identified as being the least dangerous

- Within an average household, the following items were most prevalent; Video Recorders (95\%), telephone $(86.3 \%)$, mobile phone $(88.8 \%)$, home computer $(76.3 \%)$, CD player $(90 \%)$, and Satellite $(61.3 \%)$ 
Table 5: The charting of resident's perceptions from depth interviews

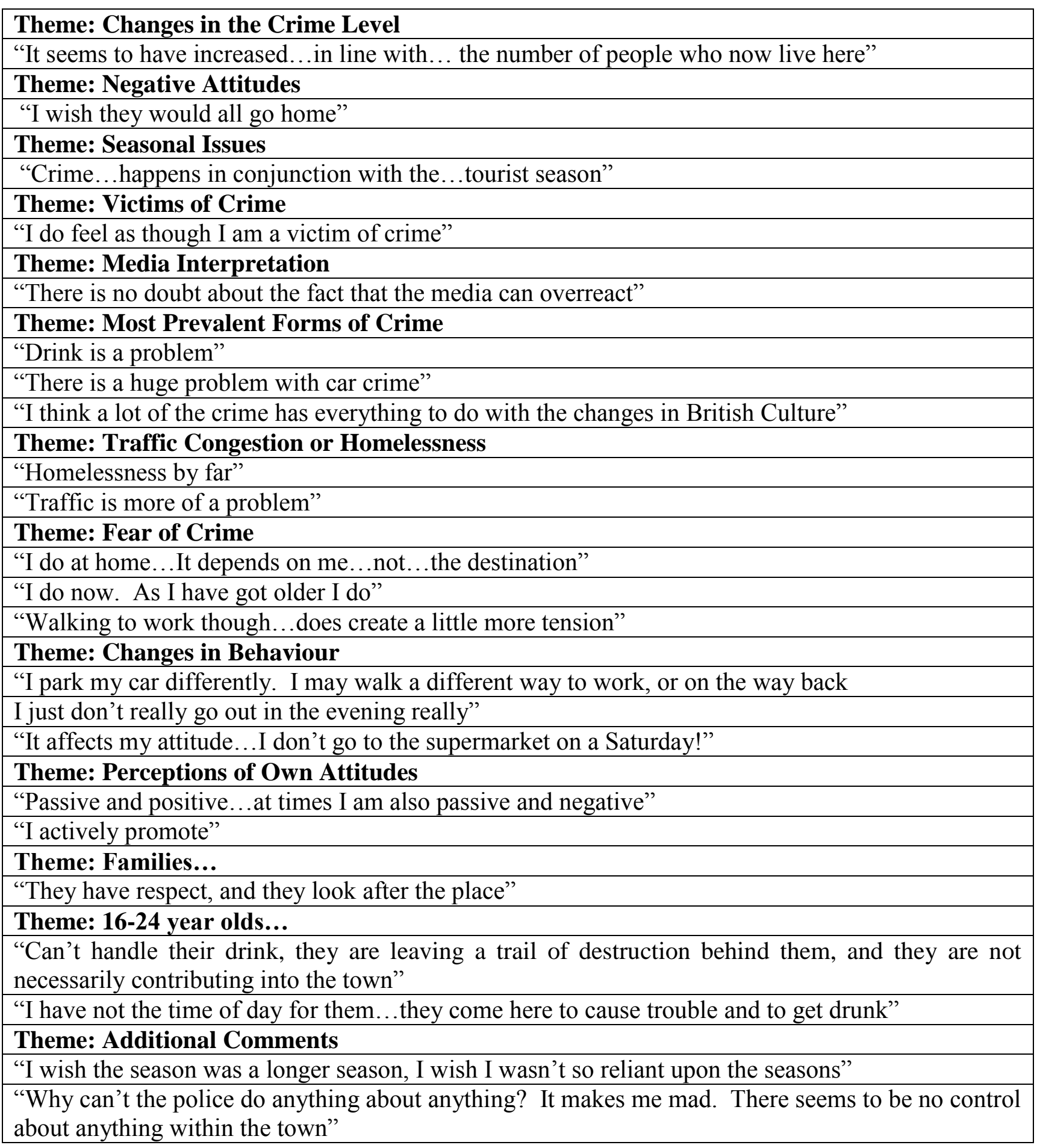




\section{Discussion and Conclusion}

From the various forms of primary data collection and analysis of the crime and tourism statistical secondary sources, it was evident that residents do change their behaviour in response to tourismrelated crime, incivilities and their fear of crime. The extent of behavioural change had some linkage with the type of host-guest relationship as well as the level of attachment, occupational engagement with the industry and the socio-cultural characteristics of the host. Tourism flows to the Southwest are seasonal (UKTS 2007), and in Newquay there is evidence of seasonal variations in criminal activity. This suggests that the relationships between tourism and crime have a similar season to the tourism industry, with the peaks and troughs of crime coinciding with the highs and lows of tourist activity. Although limitations exist, the crime statistics used in this study provided a good measure of the identification of such seasonal trends.

The variations of the tourism season, and the peaks and troughs of criminal activity were also congruent with respondent perceptions. It was apparent that, as tourism increases within Newquay, so does the experience and fear of crime. This induces behavioural changes on behalf of the permanent residents such as considering more carefully where vehicles are left overnight, and making adjustments to returning home at night. Nonetheless, it could be argued that these behavioural changes are not solely caused by an influx of tourists. Rather, it is due to the general influx of individuals over time, including new residents, casual workers and migrant workers - but is exacerbated during the summer when tourist inflows are greatest.

From the analysis of statements made, it was clear that there was a varied understanding of 'crime' within the minds of the host community. Some viewed incivilities or inconveniences in a similar way to crime, some viewed crimes as inconveniences, while others found it hard to define an act of crime in the first instance. There was also evidence of an acceptance of the benefits of tourism as attachment with the destination grew stronger. This was in line with occupational differences, as those who gain most from the industry perceived some criminal offences as being an accepted norm when tourists were in the town.

As a tourist destination, Newquay was felt to provide opportunities for criminal activity, as tourism development was believed to have caused higher levels of deviant and criminal activity. Newquay may be seen as being a venue used by criminals, tempted by the nature of the resort, the opportunity for criminal gain, and the anonymity afforded by appearing as a tourist reducing the risk of arrest. For most the common theme emerging though, was that Newquay was perceived as mainly 
attracting the 'accidental deviant', the unintentional criminal who consumed excessive amounts of alcohol and then participated in aggressive or violent behaviour as a consequence.

It was acknowledged that the level of crime and perceptions of criminal activity were consistent with the town being a tourist destination. It is clear that destinations such as Newquay, which gain a reputation as a resort for young adults result in a more hedonistic demanding type of tourist. This was supported by statements arguing that negative national media publicity that has surrounded the resort over the past few years had perpetuated the problem. It was felt that the media had increased an awareness of a hedonistic drug-sub culture by taking relatively few criminal incidents, and through sensationalistic reporting, created a myth and an overreaction to the real situation. In response to such issues, residents did not hide the realities of the area; instead they recognised that, as suggested by Brunt, Mawby and Hambly (2000:424), "victimisation at home may be associated with the so-called 'problems' of British society". Thus crimes within the destination, such as drunken and rowdy behaviour and vandalism were known to be common in many other British towns and cities.

On balance, it was recognised that while tourism contributed to an increase in crime this was related to the sheer volume of people present as opposed just being the fault of tourism per se. This is important to note as tourism was regarded as playing a major role in bringing about social change and that the industry has great potential to benefit the lives of community residents. As a result, there were some mixed perceptions of residents being the victims of crime, and having a higher level of fear within the resort. This is not surprising as tourism can be a factor of positive change as well as rather more negatively affecting traditional values, increasing crime rates, and creating social conflicts within a destination community.

Garofalo (1979:84) noted that "as age goes up, victimisation rates decrease and the fear of crime increases". There was some support for this conclusion in this study. Moreover, the sex of respondents was confirmed as also being related to the level of fear. A greater number of males perceived Newquay as being safe to walk through alone at night than did female respondents, while the secondary data suggested that males were more commonly crime victims. As a result, it seems likely that the fear of crime was out of step with the actual risk, as has been commonly found in other studies (Mawby 2000).

It was also evident within the study findings that mixed views were apparent between the business owners as opposed to the residents of Newquay who had less attachment to the tourism industry. While no statistical analysis could be applied, the level of interaction and economic dependence 
people had with the industry appeared to influence their perceptions, with those most closely linked to tourism having the most positive attitudes. The nature of the host-guest relationship and the proximity of the host residence to the tourism area were also influential upon perceptions, with those most affected by tourists having the most negative attitude. It would seem that, as Perez and Nadal (2005:927) argued, residents' estimations need to equal the benefits gained for a positive perception to be formed. It would also be possible to classify residents by their attitudes and behaviour in terms of whether they had an active or passive role in promotion of tourism development, as suggested by Carmichael (2000). Carmichael's matrix inferred that tourism is generally viewed positively by the host community, but that the type of reaction residents employ varies by occupation. The level of attachment and engagement with the industry is also reflected here in the behavioural responses of residents, with both passive and active changes occurring.

There was some evidence that supported the case that situational differences could influence the host community perceptions within the resort. One of the key findings from the CDA for Restormel was that specific areas of Newquay house different social characteristics. In this study, although there was no clear statistical association, there were variations in the level of car ownership and the location of the host's dwelling and the responses to questions concerning the experience of crime and fear of crime. The data were too limited to identify a definitive trend however.

In conclusion, this study examined the nature of Newquay residents' perceptions through an analysis of secondary data, onsite field logs and observational studies, a quantitative survey, and a qualitative analysis of residents' perceptions of crime levels, selected on occupational structure. The study explored how residents changed their behaviour in relation to crime and fear of crime within the traditional British seaside resort of Newquay. The results suggested that residents do change their behaviour by parking in different locations; socialising differently; bypassing specific streets at night; and carrying out additional security checks in the home. Respondent's perceptions of the destination and of criminal activity were found to vary in relation to occupation and engagement with the tourism industry, there were distinctions with the gender of the respondent, their age, and the level of attachment to Newquay. Perceptions were further seasonally biased and there were situational differences relating to respondent's personal circumstances.

Overall host community perceptions in tourist destinations of tourism-related crime and fear of crime would appear to identify the concept of an 'alien (tourist) culture' being perceived by local residents. Normal day-to-day activities are modified as a result of this alien culture, resulting in some deterioration in the quality of life of the resident population, while tourist levels are high. 
There is, though, an acceptance that without the presence of the 'alien' culture the community would suffer economically.

\section{References}

Agarwal, S. and Brunt, P. (2006). Social exclusion and English seaside resorts. Tourism Management, 27, 654-670.

Andereck, K. L., Valentine, K. M., Knopf, R. C. and Vogt, C. A. (2005). Residents' Perceptions of Community Tourism Impacts. Annals of Tourism Research, 32, (4) 1056-1076.

Anon. (2008). Newquay Guide. Available online at: http://www.newquayguide.co.uk/index.html (Accessed: 23.06.08

Barton, A. and James, Z. (2003). "Run to the Sun": Policing Contested Perceptions of Risk. Policing and Society, 13, (3) 259-270.

Brunt, P. (1997). Market Research in Travel and Tourism. Butterworth-Heinemann, Oxford.

Brunt, P. and Brophy, K. (2004). English Seaside Resorts and the Deviant Tourist Acta Turistica, 16, (1) 3-30.

Brunt, P. and Courtney, P. (1999). Host Perceptions of Sociocultural Impacts Annals of Tourism Research, 26, (3) 493-515.

Brunt, P. and Davis, C. (2006). The Nature of British Media Reporting of Hedonistic Tourism. Crime Prevention and Community Safety: An International Journal, 8, (1) 30-50.

Brunt, P. and Hambly, Z. (1999). Tourism and Crime: A Research Agenda. Crime Prevention and Community Safety: An International.

Brunt, P., Mawby, R. and Hambly, Z. (2000). Tourist victimisation and the fear of crime on holiday. Tourism Management, 21, 417-424.

Brunt, P. and Shepherd, D. (2004). The Influence of Crime on Tourist Decision-Making: Some Empirical Evidence. Tourism, 52, (4) 317-327.

Carmichael, B. A. (2000). A Matrix Model for Resident Attitudes and Behaviours in a rapidly Changing Tourist Area. Tourism Management, 21, 601-611.

Chesney-Lind, M. and Lind, I. Y. (1986). Visitors as Victims: Crimes Against Tourists in Hawaii. Annals of Tourism Research, 13, (2) 167-191.

Davies, B. (2003). The Role of Quantitative and Qualitative Research in Industrial Studies of Tourism. International Journal of Tourism Research, 5, (1) 97-111.

de Kadt, E. (1979). Tourism: Passport to Development? Oxford University Press, Oxford. 360 pp.

Decrop, A. (1999). Triangulation in Qualitative Tourism Research. Tourism Management. Tourism Management, 20, (1) 157-161.

Doxey, G. V. (1975). A Causation theory of Visitor-Resident Irritants, Methodology and Research Influences'. Sixth Annual Conference of Travel Research Association. San Diego. 195-198 
Garofalo, J. (1979). Victimisation and Fear of Crime. Journal of Research in Crime and Delinquency, 16, 80-97.

Garofalo, J. and Laub, J. (1978). The Fear of Crime: Broadening Our Perspective. Victimology, 3, 242-253.

Gursoy, D., Jurowski, C. and Uysal, M. (2002). Resident attitudes A Structural Modelling Approach Annals of Tourism Research, 29, (1) 79-105.

Home Office (2008). Crime Statistics in England and Wales 2006/07. Available online at: http://www.homeoffice.gov.uk/rds/crimeew0607.html

Kelly, I. (1993). Tourist destination crime rates: an examination of Cairns and the Gold Coast, Australia. Journal of Tourism Studies, 4, (2) 2-11.

Krippendorf, J. (1987). The Holiday Makers: Understanding the Impact of Leisure and Tourism. (1 ed) Butterworth-Heinemann, Oxford. $160 \mathrm{pp}$.

Lawson, R. W., Williams, J., Young, T. and Cossens, J. (1998). A Comparison of Residents' Attitudes towards Tourism in 10 New Zealand Destinations. Tourism Management, 19, (3) 247 256.

Lindenberg, K., Andersson, T. D. and Dellaert, B. G. C. (2001). Tourism Development: Assessing Social Gains and Losses. Annals of Tourism Research, 28, (4) 1010-1030.

Mathieson, A. and Wall, G. (1982). Tourism: Economical, Physical and Socail Impacts. Longman Group Ltd, Essex.

Mawby, R. (2000). Tourists' Perceptions of Security - The Risk-Fear Paradox. Tourism Economics, 6, (2) 109-121.

Moser, C. A. and Kalton, G. (1971). Survey Methods in Social Investigation. (2nd ed) Dartmouth Publishing Company Ltd, England.

MRS (2004). Crime \& Disorder Audit: Restormel. 144.

Neighbourhood Statistics. (2008). Parish Headcounts. Available online at: http://www.neighbourhood.statistics.gov.uk/dissemination/LeadKeyFigures.do? $\mathrm{a}=3 \mathrm{andb}=276908 \mathrm{an}$ $\underline{\mathrm{dc}}=$ restormelandd $=13$ ande $=16 \mathrm{and} \mathrm{g}=431262 \mathrm{andi}=1001 \times 1003 \times 1004 \mathrm{andm}=0 \mathrm{andr}=1$ ands $=121421957$ 9015andenc $=1$. (Accessed: 23.06.08

Newquay Chamber of Commerce \& Tourism. (2008). Newquay Chamber of Commerce \& Tourism. Available online at: http://www.ncct.uk.com/?menu_id=9\&menu_title=Main. (Accessed: 17th September 2007)

Perez, E. A. and Nadal, J. R. (2005). Host Community Perceptions: A Cluster Analysis. Annals of Tourism Research, 32, (4) 925-941.

Prideaux, B. (1996). The tourism crime cycle: A beach destination case study. In: Pizam, A. and Mansfeld, Y. (Eds). Tourism, Crime and International Security Issues. John Wiley, Chichester.

Ryan, C. (1993). Crime, violence, terrorism and tourism: an accidental or intrinsic relationship? . Tourism Management, 14, (3) 173-183. 
Smith, V. L. (1989). Introduction. In: Smith, V.L. (Ed). Hosts and Guests: The Anthropology of Tourism. PENN, Philadelphia. pp 1-17.

Southwest Tourism (2005). Newquay Visitor Survey: Final Report. 61. Available online at: www.newquay.org.uk/NewquayVisitorSurvey.pdf.

Surf Newquay. (2008). Welcome to Newquay. Available online at: www.surfnewquay.co.uk (Accessed: 23.06.08

Tosun, C. (2002). Host Perceptions of Impacts: A Comparative Tourism Study. Annals of Tourism Research, 29, (1) 231-253.

UKTS. (2007). UKTS 2007 - Southwest. Available online at: http://www.tourismtrade.org.uk/MarketIntelligenceResearch/DomesticTourismStatistics/UKTS/UK TS.asp. (Accessed: 23.06.08

Veal, A. J. (1992). Research Methods for Leisure and Tourism : A Practical Guide Longman Harlow.

Walmsley, J. D., Boskovic, R. M. and Pigram, J. J. (1983). Tourism and Crime: An Australian Perspective. Journal of Leisure Research, 15, (2) 136-155. 